Dialectologia 13 (2014), 27-48.

ISSN: 2013-2247

Received 9 December 2012.

Accepted 12 June 2013.

\title{
PITCH ALIGNMENT IN WELSH ENGLISH. THE CASE OF RISING TONES IN CEREDIGION
}

\author{
Stefano QUAINo \\ Alpen-Adria-Universität Klagenfurt \\ stefano_quaino@yahoo.it
}

\begin{abstract}
Welsh English and Celtic English in general are known for their preference for rising tones in declaratives. However, stating that Welsh English has a preference for rising tones is not sufficient to explain its main prosodic characteristics.

The present investigation focuses on Ceredigion, a county in West Wales with a relatively high percentage of native Welsh speakers. Several excerpts have been collected from the interviews taken for the Survey of Anglo-Welsh Dialects (1977-1979) and then processed through PRAAT: the aim is to underline the distinguishing prosodic features of Ceredigion English. For the analysis, several fundamental elements will be considered, such as alignment of the stressed syllable, characteristics of the upward movement and pitch peak. Through the detailed analysis of these key elements, it will be possible to present not only the distinguishing features of Ceredigion English, and thereby come closer to a prosodic characterization of a Welsh English accent.
\end{abstract}

\section{Keywords}

Welsh English Rises Intonation Alignment

\section{L'INTONAZIONE DEL CEREDIGION ENGLISH}

\section{Abstract}

Il termine Welsh English identifica l'inglese che viene parlato in Galles e che si differenzia dalla Received Pronunciation e dalle altre varianti di British English. Spesso si dice che l'inglese del Galles sia particolarmente musicale, tanto da essere spesso definito "sing song" (Walters 2003). Tuttavia, ben pochi 
lavori sono stati pubblicati sulla prosodia del Welsh English; uno tra questi è l'analisi di Rod Walters sul Rhondda Valley English (Galles del Sud). Volendo continuare la ricerca di Walters, mi sono soffermato sul Ceredigion, una contea nel Galles occidentale in cui la lingua gallese è parlata da gran parte degli abitanti.

Per questo lavoro, ho utilizzato il materiale della Survey of Anglo-Welsh Dialects; dopo avere selezionato alcuni spezzoni delle interviste e averli analizzati tramite PRAAT, ho illustrato le principali caratteristiche della prosodia. Estremamente interessante è l'analisi dei toni ascendenti, che sono stati descritti utilizzando le seguenti domande.

- C'è un ritardo nell'allineamento della sillaba accentata?

- Il movimento verso la sillaba accentata è rapido oppure no?

- Cosa succede dopo l'accento?

- Dove è allineato il 'pitch peak'? Subito dopo l'accento oppure con un ritardo.

Attraverso l'analisi dettagliata di questi elementi, potranno essere illustrati non solo gli elementi più comuni del Ceredigion English, ma anche le similitudini e differenze con il Rhondda Valley English; sarà quindi possibile delineare le principali caratteristiche del Welsh English.

\section{Paroli centrali}

Galles, Ceredigion, prosodia, intonazione, toni ascendenti, PRAAT, 'pitch peak'

\section{Introduction}

Welsh English (WE) is a general term to describe the Englishes spoken in Wales, which differ from RP (Received Pronunciation) and other British accents and varieties. Some of the most characteristic features of WE are its intonation and prosodic patterns, which have been defined by Walters (1999) as tuneful and "sing-song".

Welsh English and Celtic English in general are known for their preference for rising tones in declaratives, as shown by Cruttenden (1995), Gimson (2008), Tench (1990), Walters (1999). Gimson (2008: 289) states that "rises are more frequent on declaratives than in RP and [sic] may typically be the most frequent tone on declaratives". Cruttenden (1995: 155) even considers the case of Liverpool English, stating that the influx of people from Scotland and Ireland has caused an increase in the number of rises if compared with RP.

Despite being musical, very limited work has been carried out on prosody of Welsh English and its intonation patterns. The only thorough research in this field has been undertaken by Rod Walters (1999), who analysed the main prosodic features of Rhondda 
Valley English in South Wales (RVE). The present research will focus on the English spoken in Ceredigion (CE), a county in West Wales where the Welsh language is spoken by a relatively high percentage of the population. For this analysis, several excerpts from the interviews taken for the Survey of Anglo-Welsh Dialects have been collected and then processed through PRAAT.

It will also be interesting to compare the present results with those offered by Walters. A perfect comparison is not possible, since the methods used are not completely similar; in addition, two researchers not necessarily arrive at the same result, even when using the identical methods. However, comparing CE and RVE will underline the main similarities of the two varieties and thereby come closer to a prosodic characterization of a Welsh English accent in general.

\section{Informants, alignment and methods of analysis}

The present research is based on a number of excerpts from the Survey of AngloWelsh Dialects (SAWD). The SAWD was a project conceived by David Parry, a dialectologist at Swansea University, in the late 1960s. After preparing a set of questions, Parry and his colleagues (starting from the 1970s) began to visit many villages in Wales and interview local people (aged between 60 and 80 ); the project continued till the 1990s, when a comprehensive volume with much information about the phonetics, phonology, syntax, morphology and vocabulary of Welsh English was able to be published. The interviews that have been used for the present research were prepared between the late 1970s and the early 1980s.

The present prosodic analysis has been initially carried out via a modified version of ToBI, a method which has also been used by Walters in his research on Rhondda Valley English (1999). The attention will be focused on contours found at pitch accents, which are composed of two distinguishable movements:

1. The first contour point is the movement towards the stressed syllable.

2. The second contour point is the movement from the stressed syllable. 
Intonation analysis will be carried out via the measuring and classification of the contour points of utterances: $\mathrm{H}$ will identify a contour point which is higher than the previous one, which means that the pitch has risen; $L$ will be used to describe a contour point lower than the previous one. If the pitch does not present relevant upwards or downwards movements, the specific contour point will be marked with a 0 . As a result, $H^{*}+H$ describes a pitch accent whose both first and second contour point are rising; $L^{*}+H$, instead, identifies a pitch accent which is formed by an initial fall and a subsequent rise.

However, if one wants to present a more detailed analysis of the language, it is not sufficient to determine whether the pitch movement is upward or downward, nor is it by stating the numerical value of the contour points; ToBI analysis alone cannot present the real distinguishing prosodic features of a language. Since pitch movements are found in every language, one should wonder whether they share the same characteristics or they present differences: for example, matters of extreme interest are related to the starting point of the rise and the position of the pitch peak. Alignment is the theoretical concept which comprises this kind of analysis. Although many aspects of alignment remain obscure, it can nonetheless be stated that alignment is 'highly lawful and can be systematically influenced by a range of phonetic and phonological effects' (Ladd 2008: 169).

Alignment is strictly connected to the realisation of the tones and it is defined by Ladd (2008: 169) as the "temporal coordination [of tonal targets] with the consonants and vowels of the segmental string". He also adds that alignment is "a phonetic property, namely the relative timing of events in the FO contour and events in the segmental strings" (Ladd 2008: 179). The segmental events that are found during a stressed syllable could influence the realisation of the prosodic patterns: for example, the difference between voiceless and voiced consonants might lead to a different intonation pattern of the following vowel.

When analysing alignment, two features constitute the main focus of interest, namely the beginning of the rise and the position of the pitch peak. It is necessary to determine the exact position of the starting point of the upward movement, since certain languages show a preference for early rises, while others prefer late rises. 
After establishing the starting point of the upward movement, the attention is then shifted to the pitch peak. The $\mathrm{H}$ tone is an instance of rising intonation which carries the pitch from a lower to a higher point, so that during its pronunciation the FO will be characterized by an upward movement. At one specific point within the syllable, the pitch will reach its peak: it is interesting to determine whether the peak has occurred towards the onset of the syllable (beginning), the midpoint or the end. The peak of an $\mathrm{H}$ tone always relates to a prominent syllable, and in this connection Ladd (2008: 179) observes that:

We may expect to find a peak of FO somewhere in the general vicinity of that syllable, not several syllables earlier or later, but the peak may be early in the syllable or late, and indeed it may be outside the temporal limits of the syllable altogether.

Comparing alignment is a good means to reveal the prosodic differences among languages or dialects: Ladd states that Scottish Standard English has a later alignment of the peak if compared to RP, while a similar difference has been found between the German dialects of the North and those of the South. Dutch, instead, has a tendency for early alignment of pre-nuclear rising accents, while the position of the peak is influenced by the quality of the vowel: a long vowel will have its peak toward the end of this vowel, while a short one will have its peak in the following consonant (Ladd 2008, 176).

The present paper will focus on pitch alignment in Ceredigion English: the interest will fall on those contours which carry either a rising or a level movement, regardless if it is towards or from the stressed syllable. Although rises and level tones are not completely similar, they are both non-falling movements.

In addition, pitch accents should also be given the Most Prominent Semantic Element (MPSE) status or found at the very end of an intonational phrase, so that they carry a terminal tone. The MPSE identifies the word which has been given the major focus by the speaker; talking is a way of communicating information with others, with speakers always having a specific goal in their mind. They want to share a message with others, and intonation is a major tool for this orientation. Utterances have been be analysed in relation to previous questions and if no obvious question / answer structure is present, 
two or three previous statements in the communication have been taken into consideration.
A: "Where is John flying on Sunday?"
B: "John is flying to Rome on Sunday".

In the example above, the obvious MPSE is "Rome", since it is a logical answer to A's question. All other semantic elements could be removed (John, flying, Sunday), since they are simply redundant. The MPSE could be compared to the nucleus, but I prefer to distinguish the two terms. The nucleus, also known as tonic syllable, is the 'most prominent, or salient, of the stressed syllables in a given unit' (Tench 1990: 53). Since the nucleus is a strongly accented syllable, its identification is enabled via tone and intensity values: the tonic syllable is usually marked by the highest pitch or the greatest pitch movement throughout the unit; along with this, it is usually introduced by a crescendo and followed by a decrescendo. The analysis of rising tones will be carried by considering a series of questions, such as:

- Is there any delay in the alignment of the stressed syllable?

- The intensity peak is aligned at the beginning of the syllable or with a delay?

- Is the upward movement towards the stressed syllable rapid or not?

-What occurs to the pitch after the stress?

-Where is the pitch peak aligned? Immediately after the stress or is it delayed?

Only through the detailed analysis of these key elements will it be possible to present the distinguishing features of Ceredigion English and thereby come closer to a prosodic characterization of a Welsh English accent. 


\section{3. $H^{*}+H$ and $H^{*}+L$. Differences and similarities}

Example \#1 and Example \#2 present two pitch accents coming from the same utterance (you show the house)

\section{Example \#1}
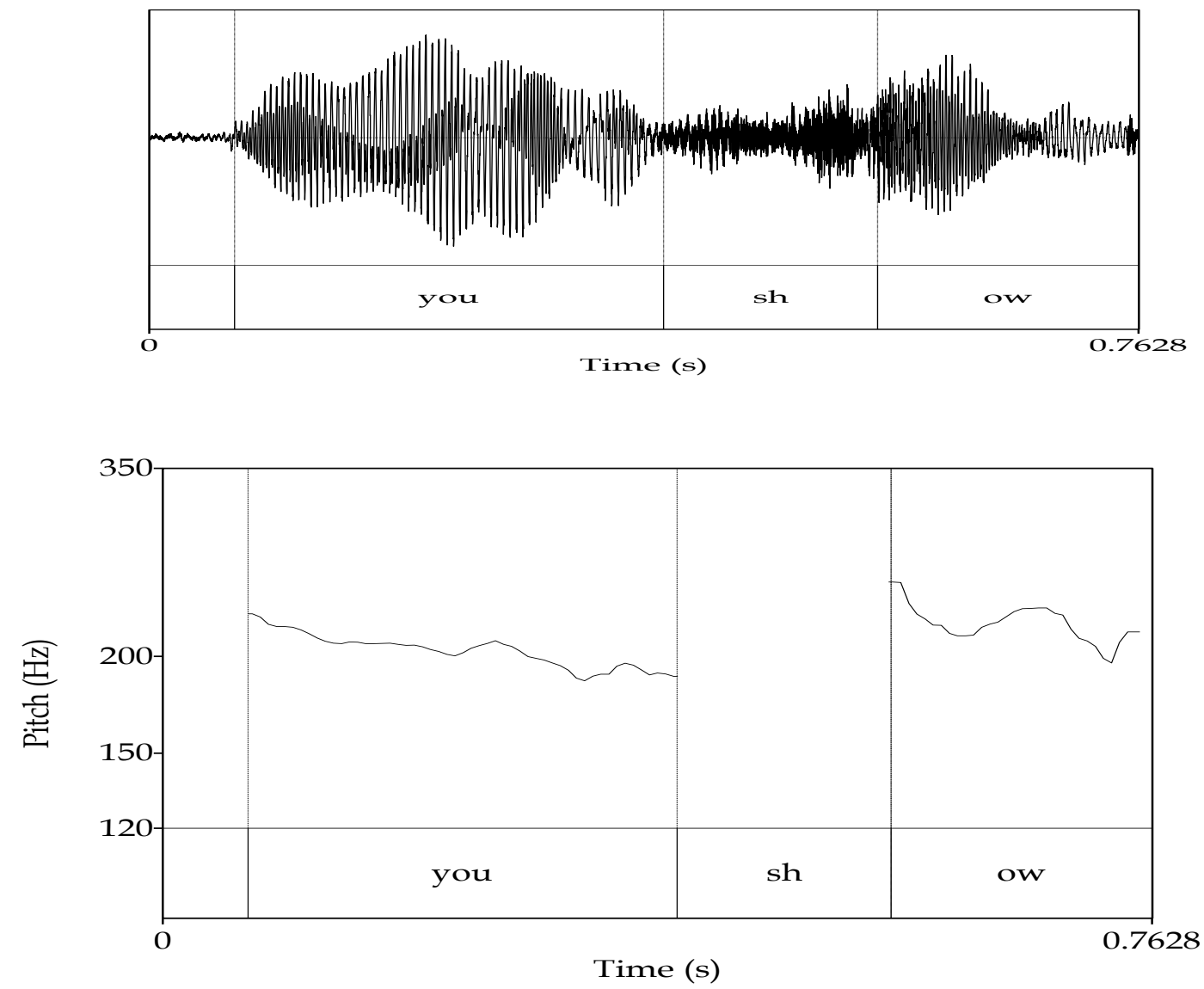

After the falling movement at "You", the pitch begins its rise: there is a sudden interruption of the pitch line, which is caused by the $/ \mathrm{J} /$ being unvoiced; it reappears at a later stage in a much higher position, where the consonant is changed into a vowel. The pitch begins to fall, so that the contour point is reached during the downward movement: when the fall is completed, the pitch is allowed to rise again.

A similar situation can be found on the terminal tone (Example \#2): the contour point at "the" (unstressed syllable) and the first one of "house" have recorded the same pitch height, but they are not joined by a steady pitch but by a fall-rise movement. 


\section{Example \#2}
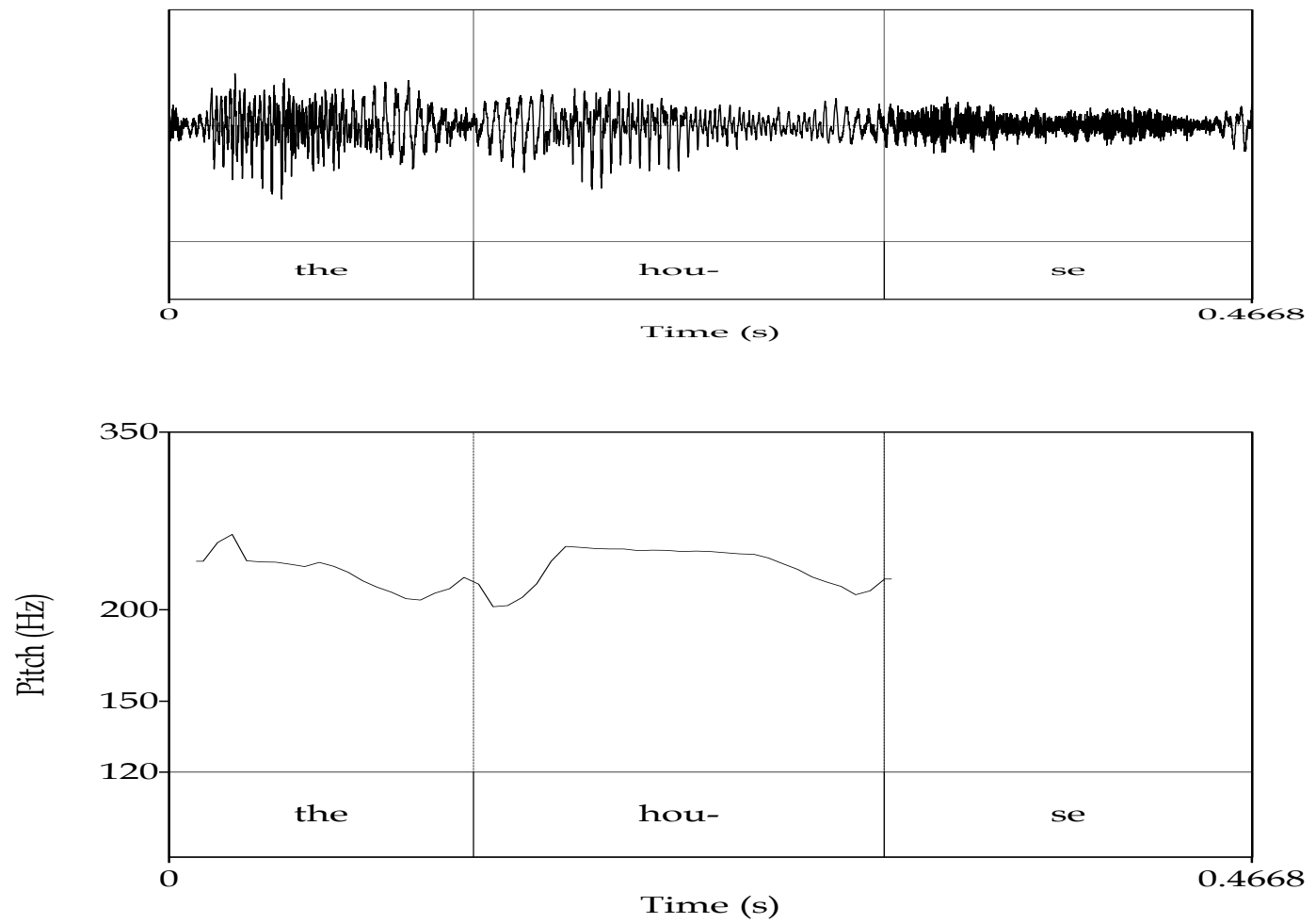

The pitch accent "yokes" in Example \#3 has been marked with $\mathrm{H}^{*}+\mathrm{H}$, but it is not similar to "show" and "house" as presented in Example \#1 and Example \#2. The word begins with a semivowel $/ \mathrm{j} /$, which is used by the speaker for the first tone. The pitch starts to move upwards after "the", which is the lowest point of the utterance. However, rather than an immediate rise (the brief rise and the short fall at the very end of "the" can be overlooked), there is a long instance of level intonation; only after 121 ms does the pitch begin to go up, reaching its intensity climax when the $/ \mathrm{j} /$ is changed into a $/ \mathrm{o} /$; this is the first contour point, which is followed by a rising tone. 


\section{Example \#3}
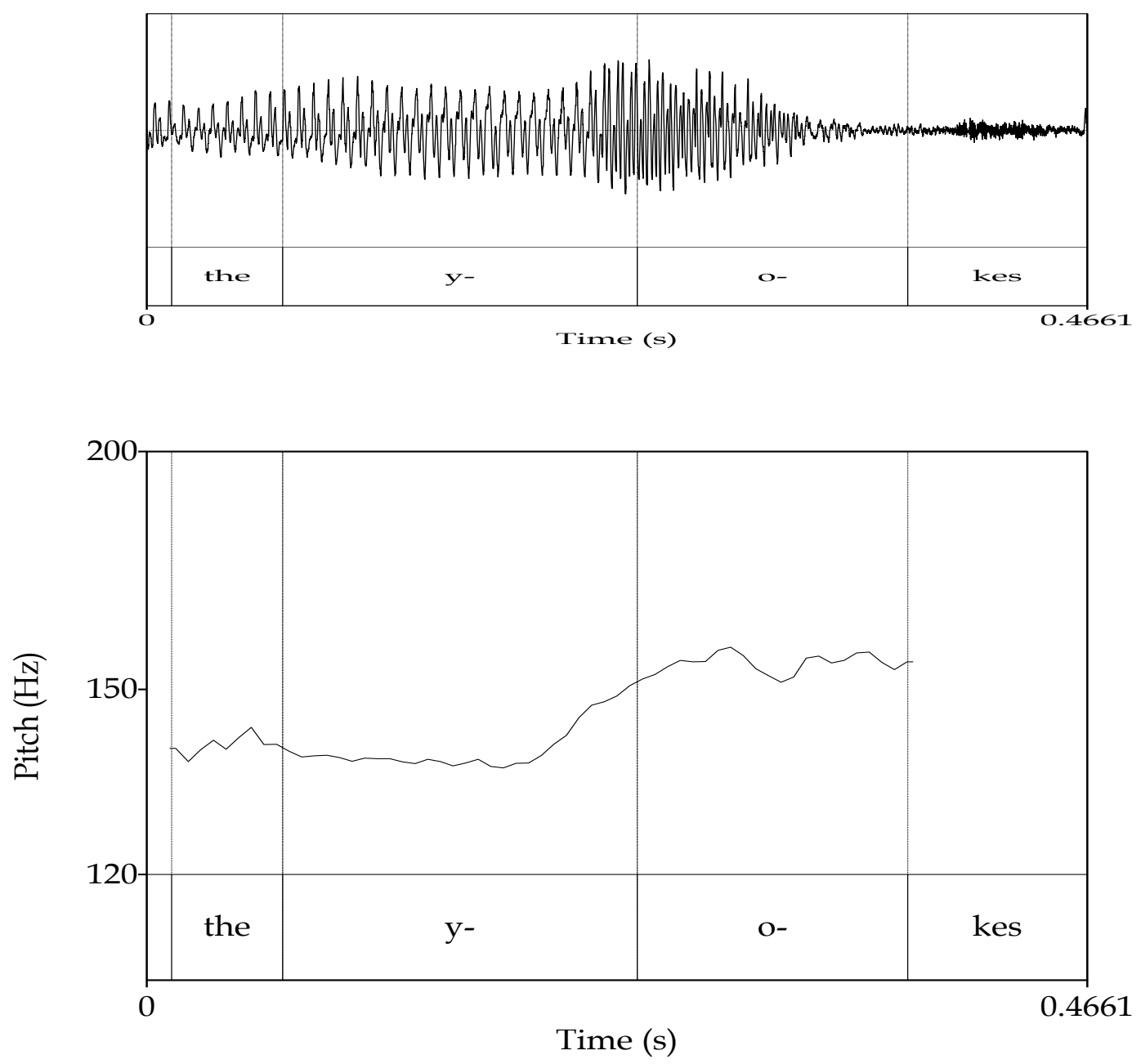

After analysing the pitch accents of Example \#1, Example \#2, Example \#3, an interesting feature seems to emerge, namely the late alignment of the intensity peak in the $\mathrm{H}^{*}$ : as the graph shows, the stress occurs with a delay of at least $70 \mathrm{~ms}$. It appears that the first contour point of the pitch accent is preceded either by a sag (as in "show" and "house") or by a long static tone (as in "yokes"). Then, semivowels play an important role during the movement towards the stressed syllable. The following examples will confirm these hypotheses. 


\section{Example \#4}
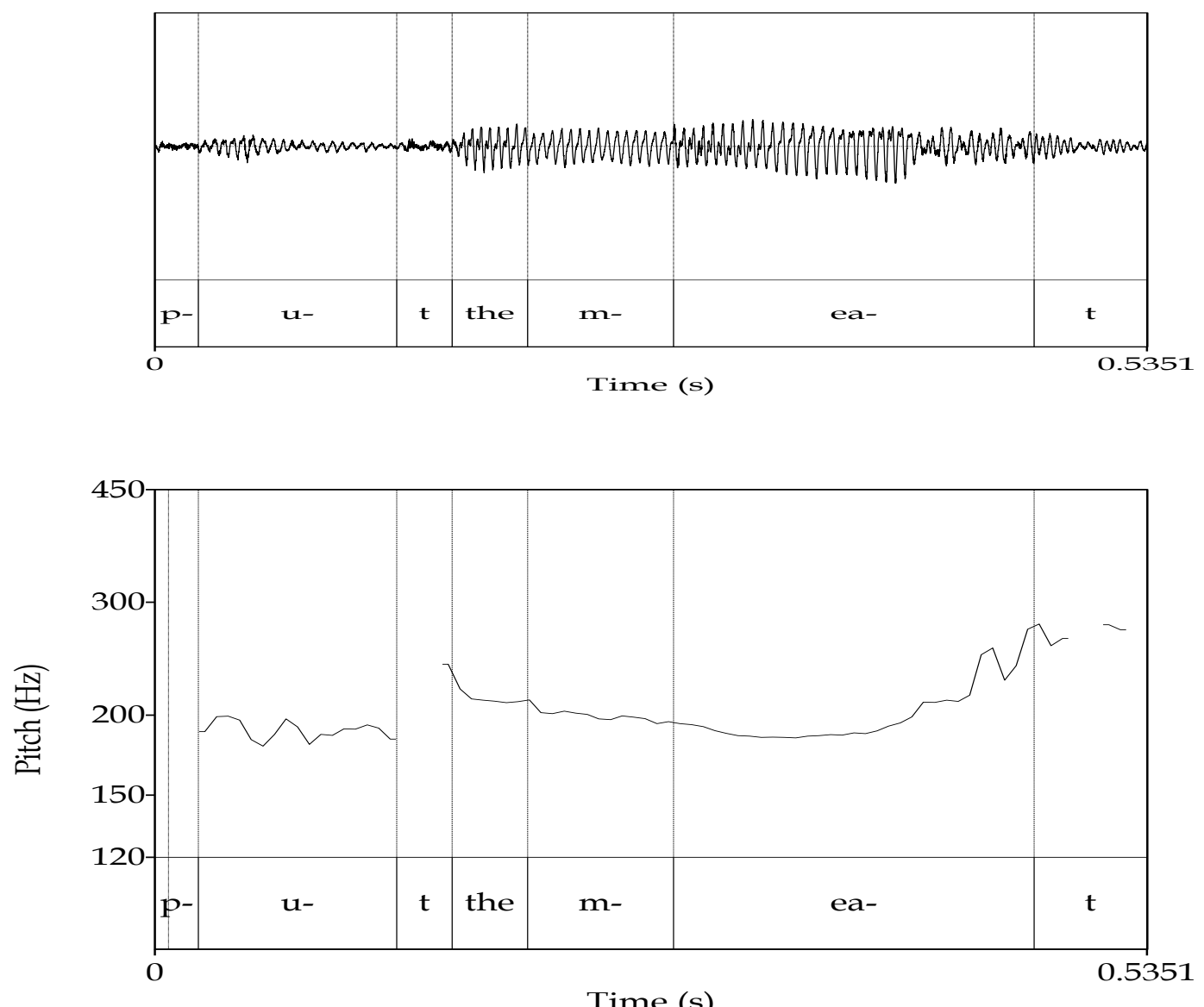

In Example \#4 "meat" is extremely lengthened, being held for $328 \mathrm{~ms}$. When a vowel is so extended, the late alignment of the $\mathrm{H}^{*}$ is an obvious consequence.

The first four examples have presented the main features of $\mathrm{H}^{*}+\mathrm{H}$ pitch accents. The attention now will be shifted to the $\mathrm{H}^{*}+\mathrm{L}$. Example \#5 presents an utterance which has been divided into two IPs: two pitch accents can be analysed, "stick in" (\#5a) and "ween" (\#5b), both of which have been marked $H^{*}+\mathrm{L}$. 
Dialectologia 13 (2014), 27-48.

ISSN: 2013-2247

\section{Example \#5a}
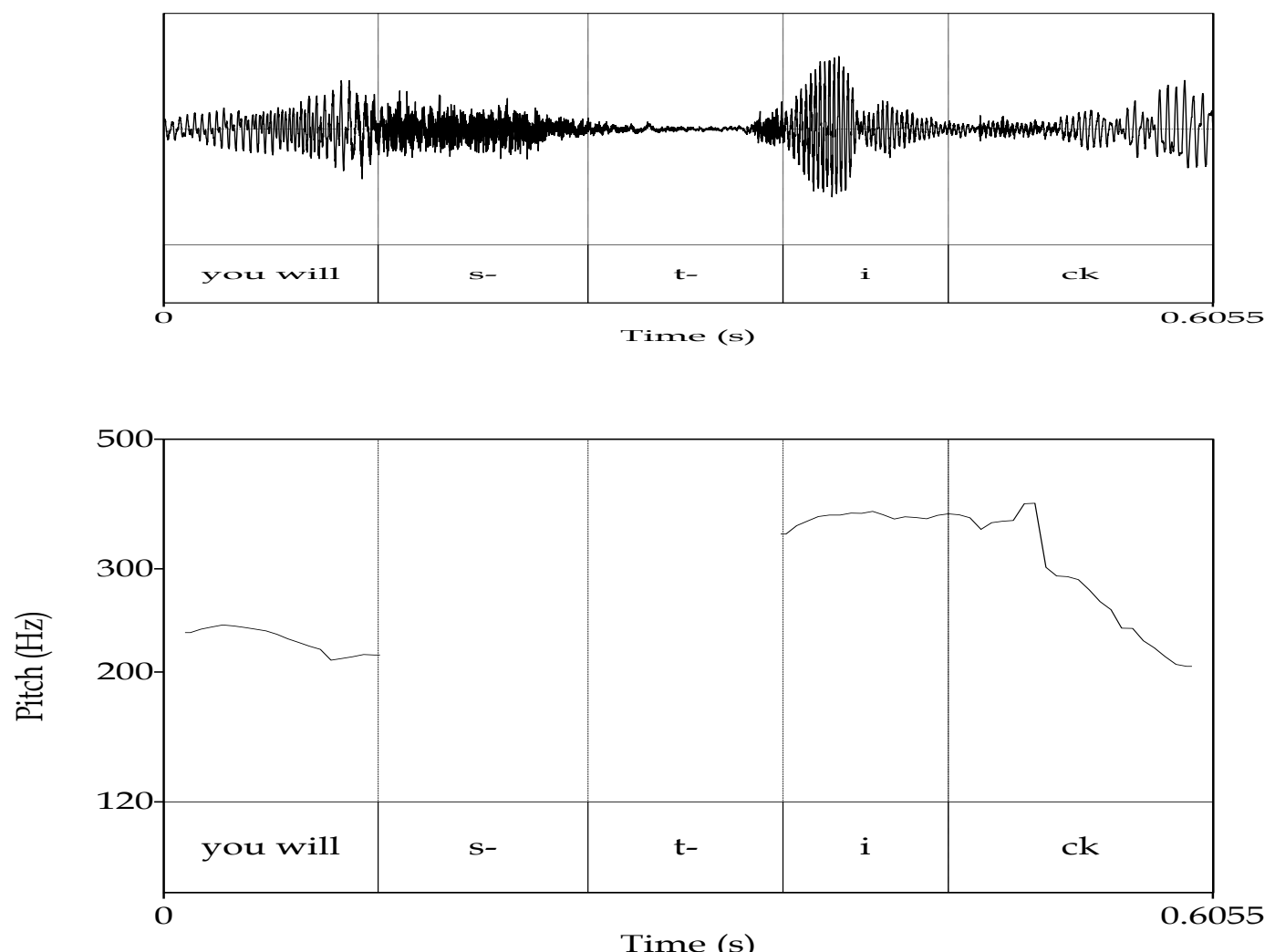

\section{Example \#5b}

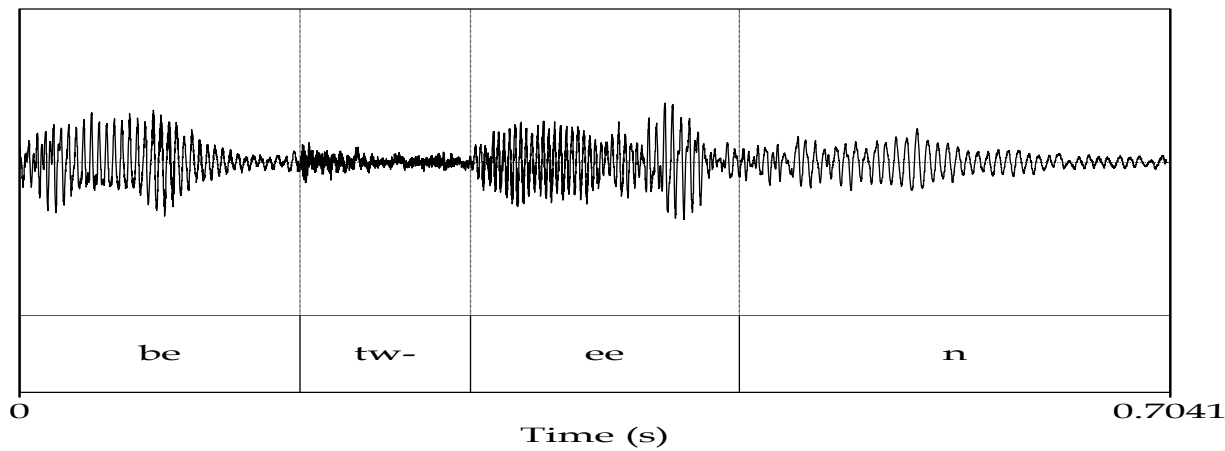




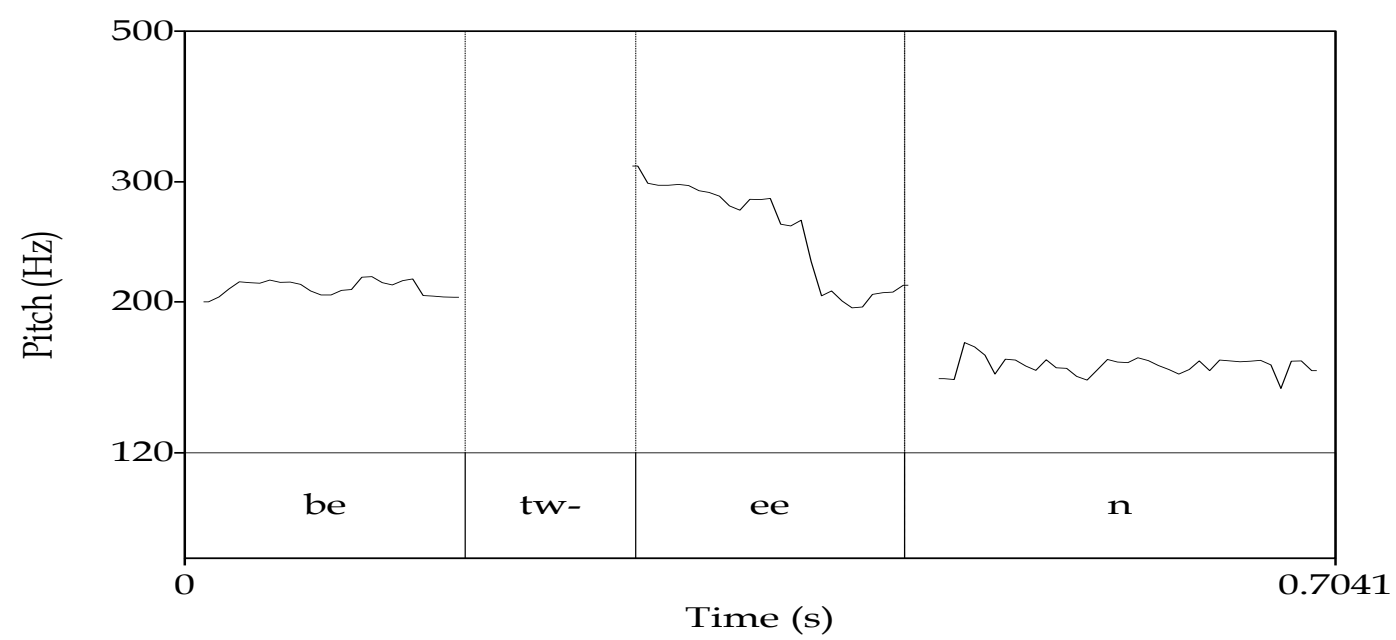

Example \#5a presents a short vowel /I/: as appears from the graph, the $\mathrm{H}^{*}$ is perfectly aligned, not being preceded by any effect, while the intensity peak occurs after a very limited delay. It should be said that late alignment is usually connected to lengthening, so it is rather obvious that a short vowel does not lead to any delay. While in $\mathrm{H}^{*}+\mathrm{H}$ there is an evident delay of the intensity peak, in $\mathrm{H}^{*}+\mathrm{L}$ this is considerably reduced.

However, even "between" (Example \#5b) does not present substantial differences; in this case, the $/ \mathrm{w} /$ is not a real semivowel, but rather a sibilant sound which could resemble a whistle; that is the reason for the disappearing of the pitch line after the $/ \mathrm{t} /$. When the consonant is changed into the long vowel/i:/, the $\mathrm{H}^{*}$ is marked after a short delay, which is much shorter than what occurs in $\mathrm{H}^{*}+\mathrm{H}$ (less than $20 \mathrm{~ms}$ ).

\section{Example \#6}

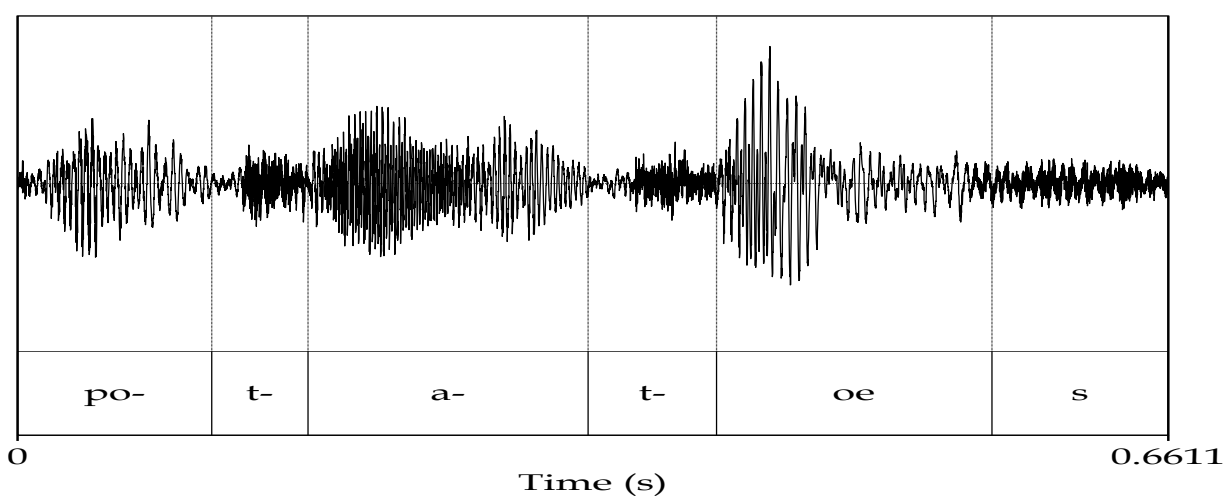




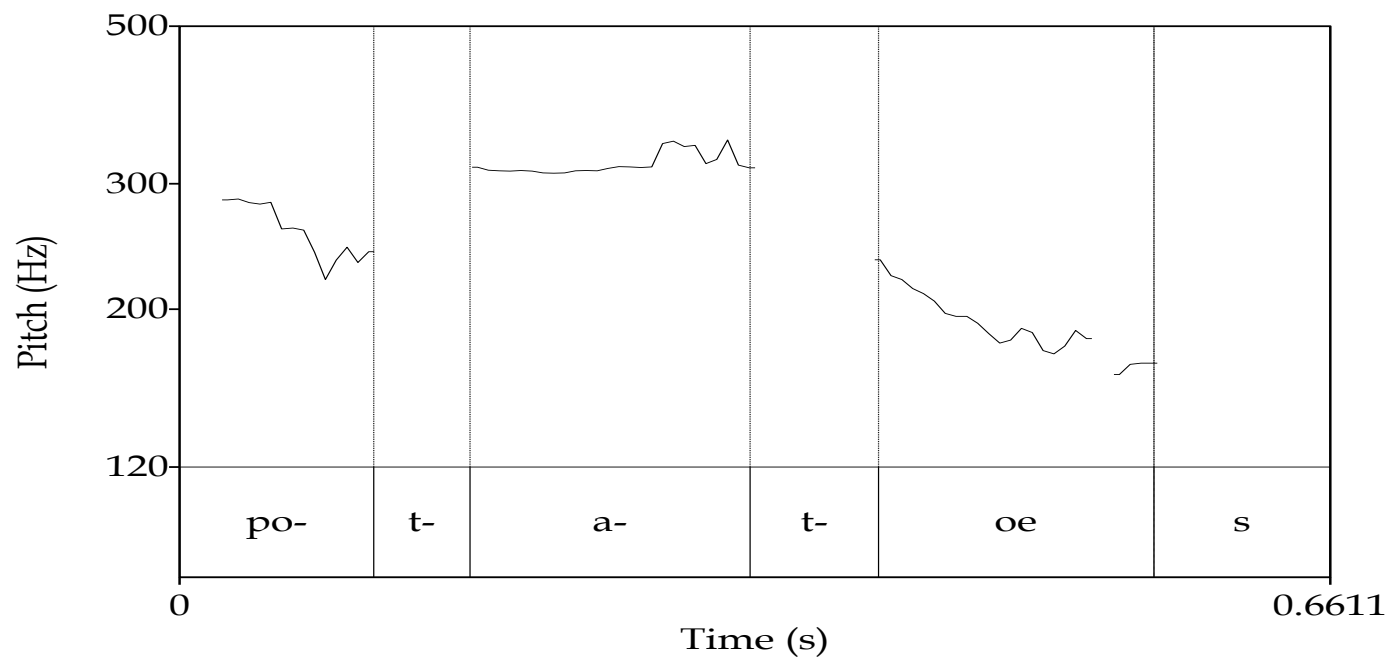

A similar event also occurs in Example \#6. The intensity peak of the $\mathrm{H}^{*}$ is reached after a limited delay.

\section{Example \#7}
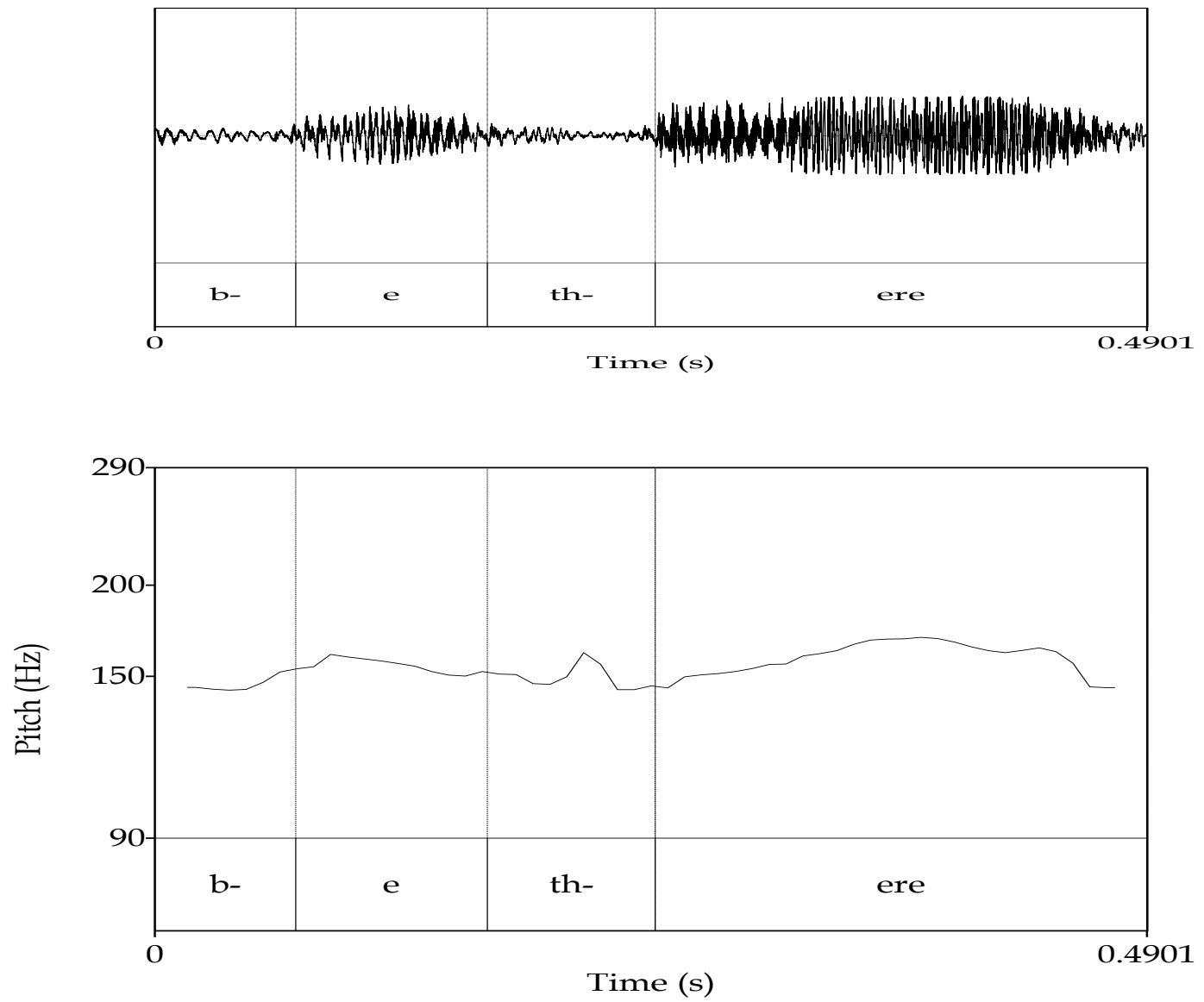
Only when vowels are extremely lengthened does late alignment occur in $\mathrm{H}^{*}+\mathrm{L}$. This feature is shown by Example \#7, where the vowel / $\varepsilon$ :/ in "there" has been held for 250 ms. When the fricative is changed into the $/ \varepsilon: /$, the pitch has a very slight rise (from 148 $\mathrm{HZ}$ to $152 \mathrm{HZ}$ ), which can be considered as a level tone movement: this static tone, which is kept for $75 \mathrm{~ms}$, precedes the real rise and causes the late alignment of the $\mathrm{H}^{*}$.

\section{Example \#8}
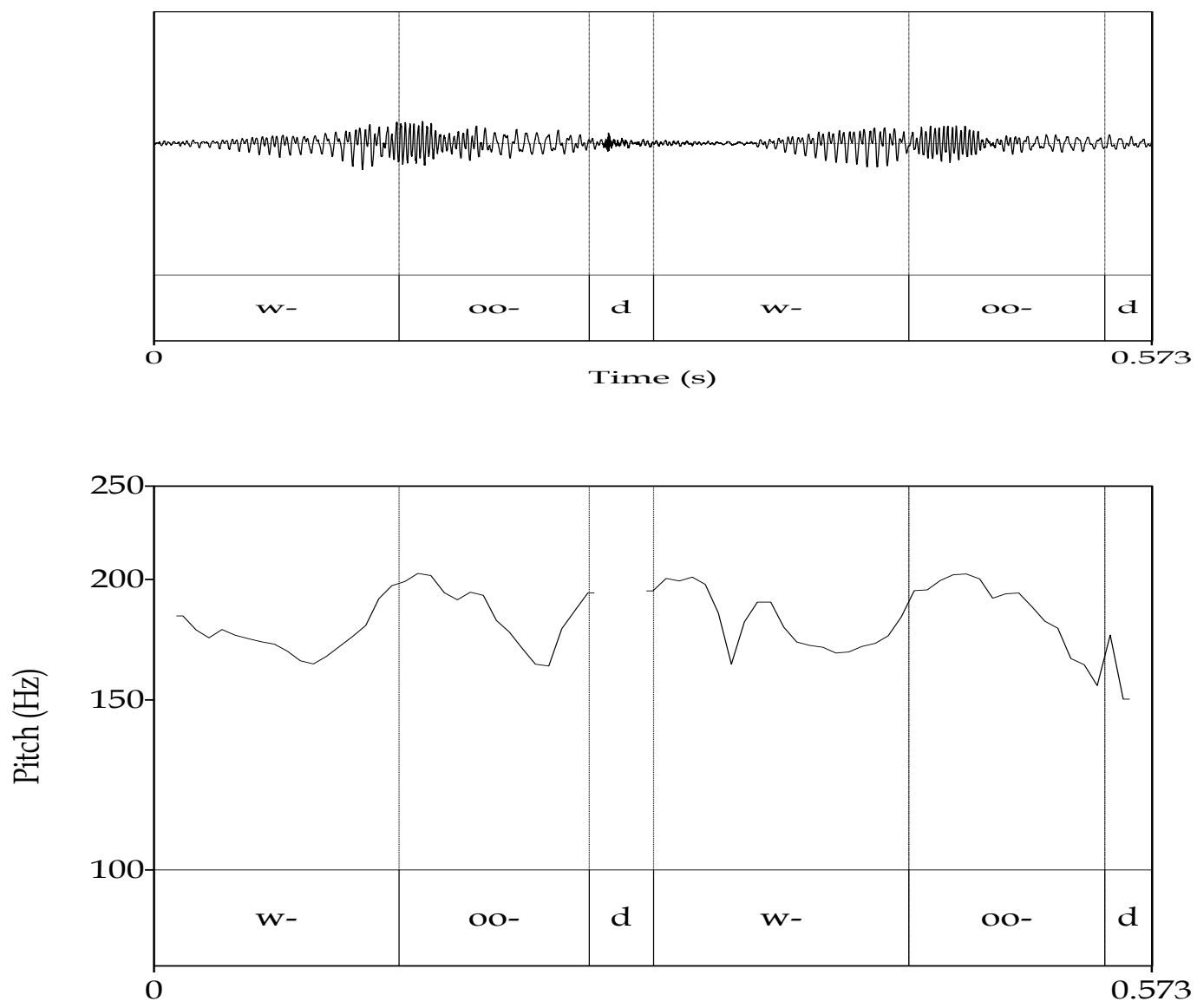

Time (s)

Example \#8 is useful in revising the role of semivowels. As one can notice, the pitch movement is carried by the $[\mathrm{w}]$, while the $\mathrm{H}^{*}$ is marked when the semivowel is changed into the full vowel. 


\section{Main features of $L^{*}+H$}

After describing the pitch accents which carry an upward first tone, let us shift our attention to the initial movements which present a fall. The focus will be mainly on $\mathrm{L}^{*}+\mathrm{H}$ rather than $\mathrm{L}^{*}+\mathrm{L}$ : because of the rising tone, in $\mathrm{L}^{*}+\mathrm{H}$ there is an abrupt pitch change of direction, which obviously does not occur in $L^{*}+\mathrm{L}$. During the analysis, three elements / questions will be considered:

- Where is the $L^{*}$ aligned?

- Does the pitch immediately rise after the pitch or does it continue to fall?

- When does the rise $(\mathrm{H})$ start?

In his research on Rhondda Valley English, Walters (1999; Chapter 5 - Section 4.4) claims that:

A phonetic feature of rising tone contours, particularly $\mathrm{L}^{*}+\mathrm{H}$ and $\mathrm{O}^{*}+\mathrm{H}$, is that they may be heard to 'sag' during the course of the stressed syllable before their subsequent rise. In $\mathrm{L}^{*}+\mathrm{H}$ contours, this is seen as late alignment of the $\mathrm{L}^{*}$ in the syllable.

Walters (1999; Chapter 5-Section 4.4) also presents a series of examples where he tries to calculate the 'distance of the contour point into the stress vowel': this is not a fixed value, since in his examples, it varies between $29 \%$ (on "Tom" from the utterance "Tom Evans was... was a strict secretary), 43\% (on "Cardiff" from the utterance "I walked from Cardiff") and 78\% (on "Maerdy" from the utterance "and my father was working in the colliery in Maerdy"). In another example, he analyses the utterance "there was no children", where the main accents falls on "child": here he states that the $L^{*}$ "is reached during the /I/ of the following stressed vowel".

As previously mentioned, a perfect comparison between the present research and Walters' is not completely possible. However, the data on RVE presents an interesting feature: the falling movement tends to be long and lengthened, while the subsequent rise 
is delayed; the analysis will now determine whether Walters' assumptions are also valid for CE.

\section{Example \#9}
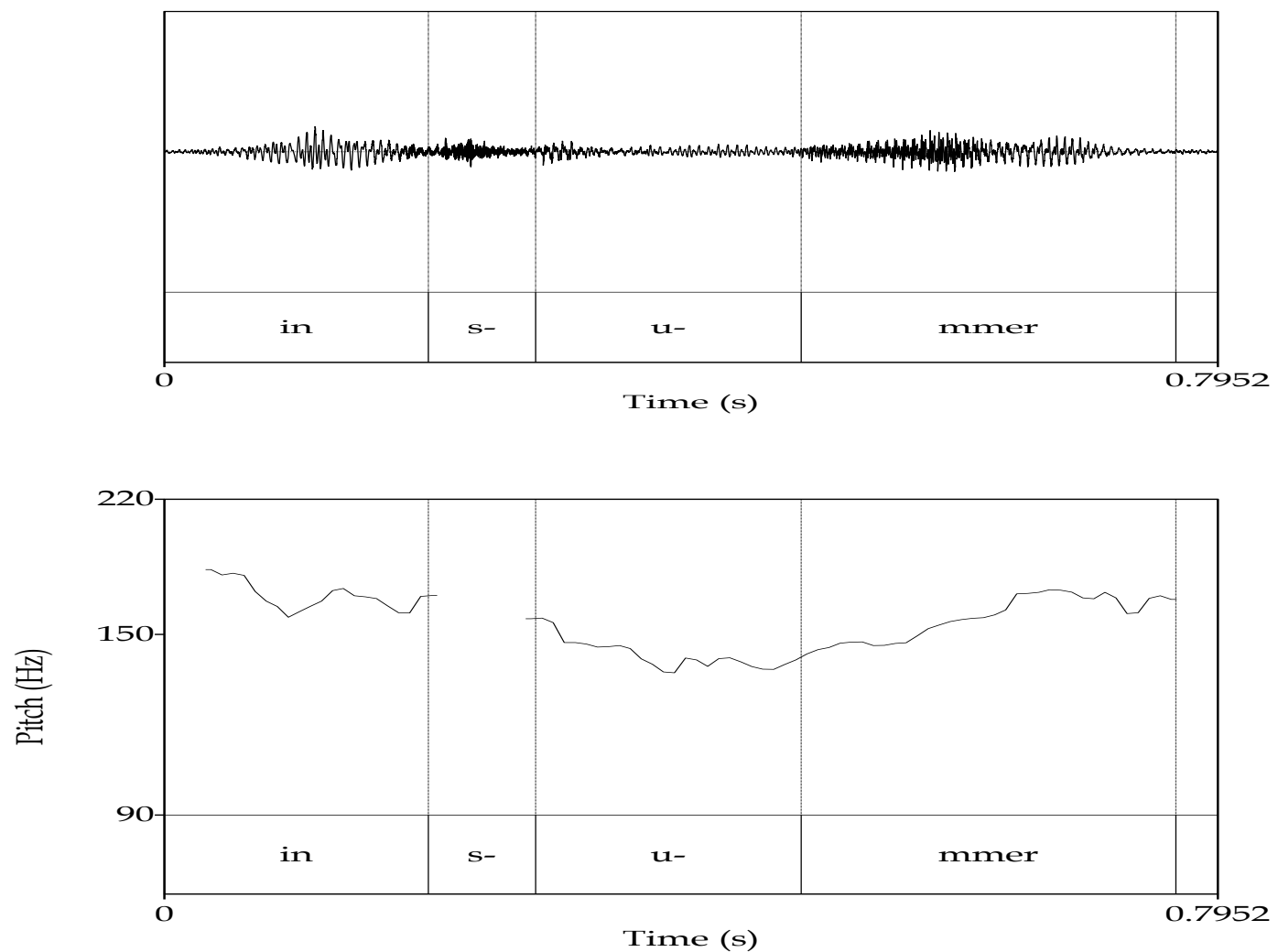

In "summer" (Example \#9), the $L^{*}$ does not have much delay, since it is marked immediately after the $/ \mathrm{s} /$ changes into the $/ \Lambda /$; however, the pitch continues its downward movement for other $105 \mathrm{~ms}$. When the fall is complete, the pitch does not begin its rise, but is kept at the same level for other $62 \mathrm{~ms}$ before the upward movement can finally start: the $\mathrm{H}$ is marked after $125 \mathrm{~ms}$, which means that the pitch does not stop when the intensity peak is reached, but it continues to rise.

Example \#10 presents an interesting excerpt, with the focus of the analysis "harness": first of all, the $L^{*}$ has a delay, being aligned no less than $78 \mathrm{~ms}$ into the syllable. When the fall is complete, the pitch does not begin to rise immediately, but it is held at the bottom through a static tone, for at least $60 \mathrm{~ms}$. 
Dialectologia 13 (2014), 27-48.

ISSN: 2013-2247

\section{Example \#10}
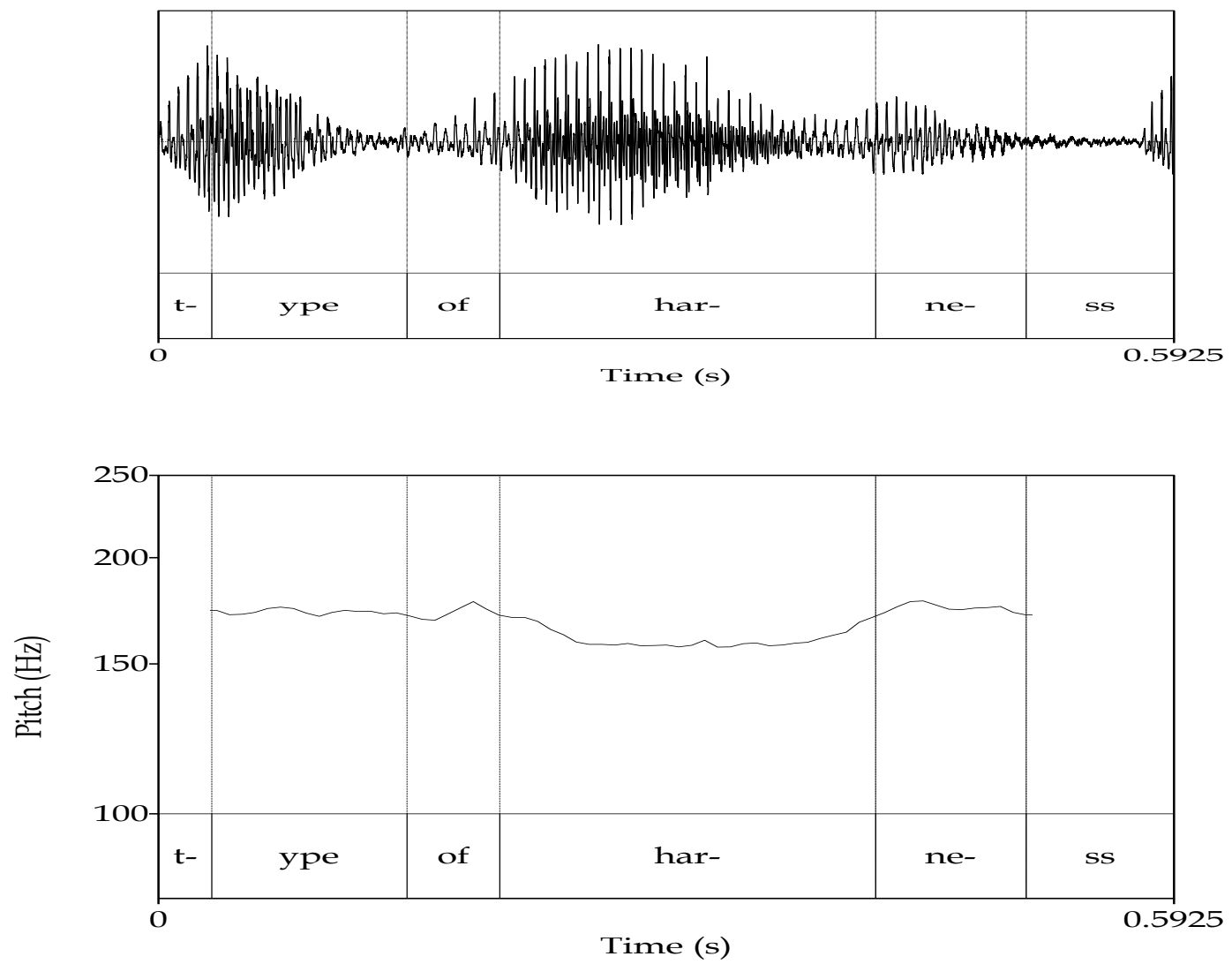

Example \#11

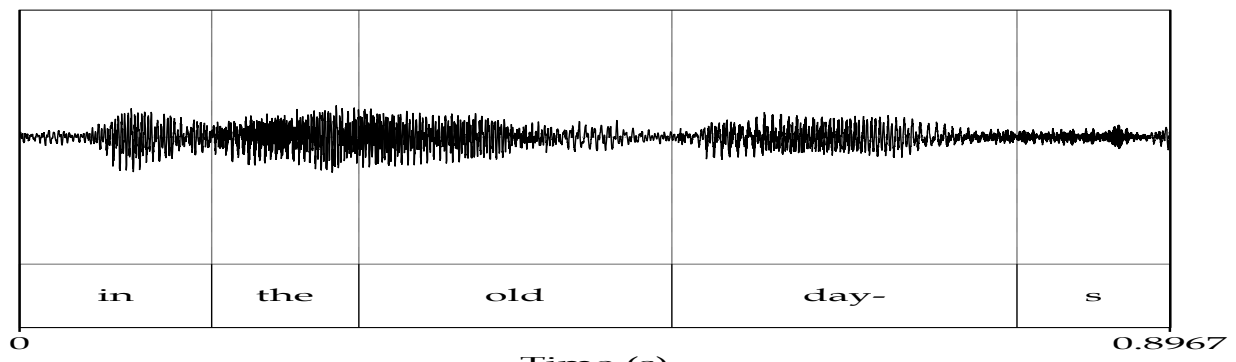

Time (s) 


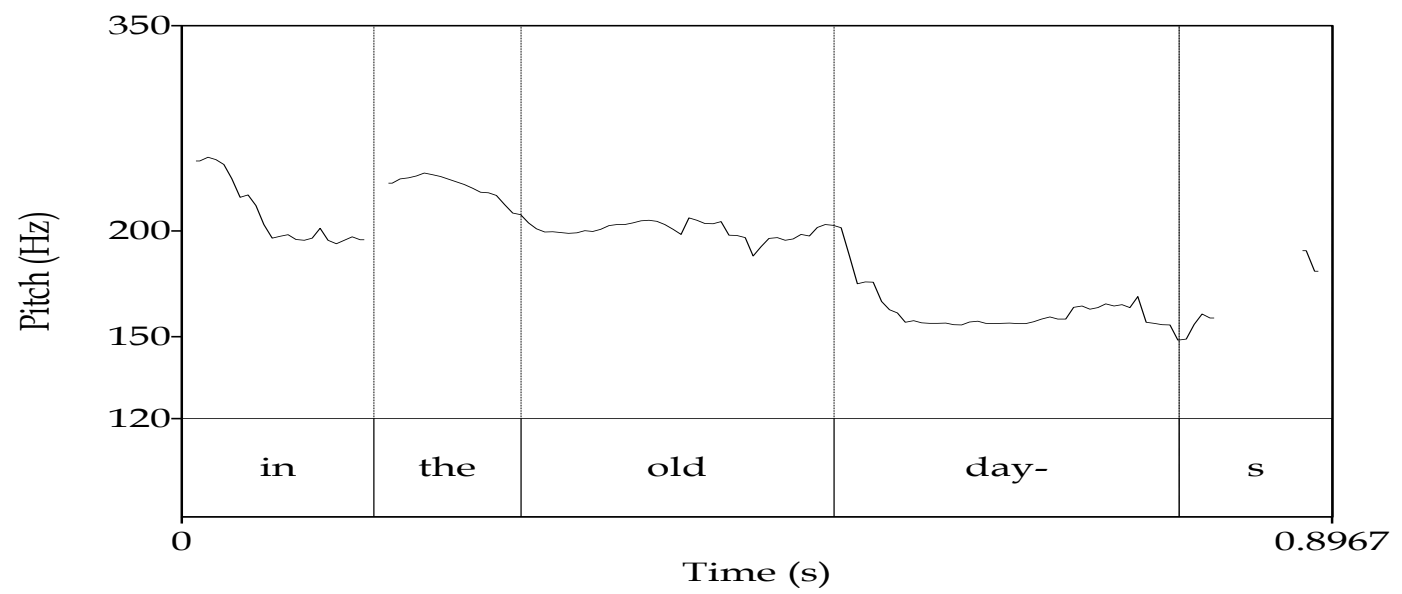

Example \#11 presents some differences which have to be remarked on: the falling movement on "days" is definitely steeper and deeper than those presented in the presented in the previous examples. Interestingly, the alignment of the $L^{*}$ is delayed, but not as much as in the other pitch accents, since it is marked less than 50 ms into the syllable. However, it is the static tone preceding the rise which has been increased: the upward movement does not start until 116 ms have passed, with the /e/ changing into the $/ \mathrm{i} /$.

\section{Example \#12}

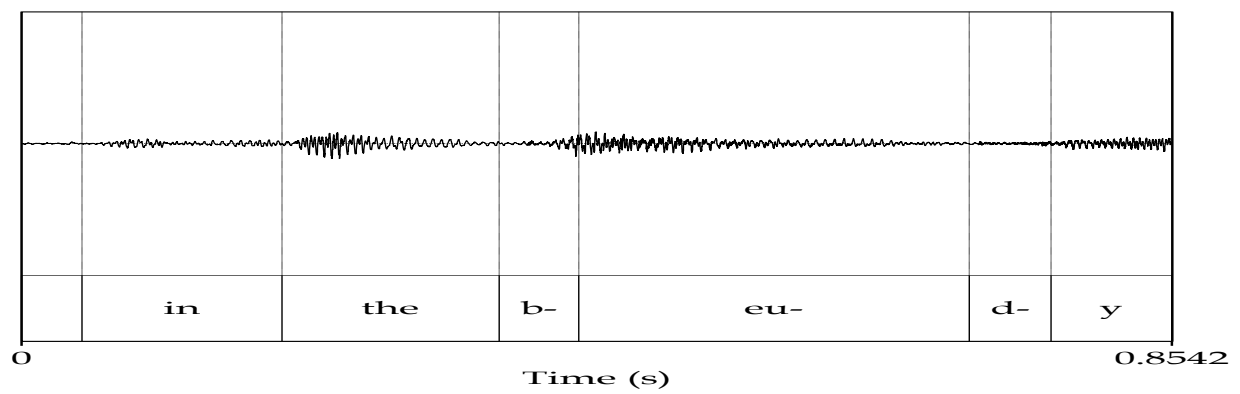




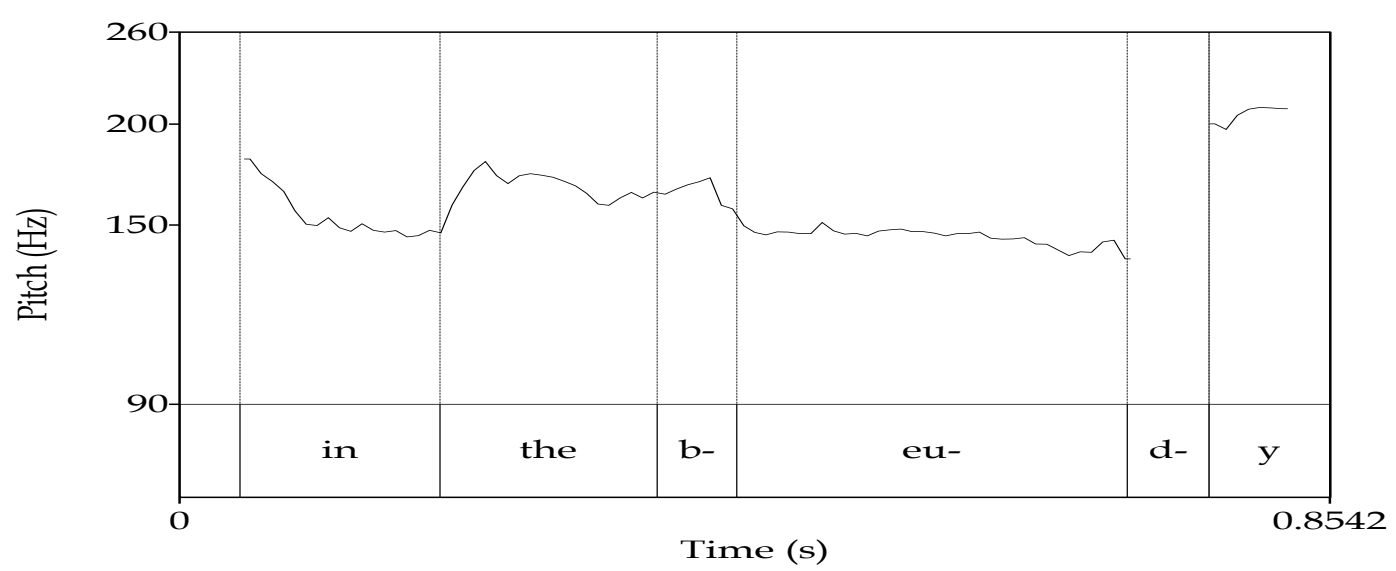

In Example \#11, the pitch accent "days" has a slightly different pattern if compared to the other $L^{*}+H$, since it presents a steeper fall, a minimum late alignment of the $L^{*}$ and a very long static tone which delays the rise; however, it has still been considered as a single tone pitch accent. A similar pattern can be found in Example \#12 on the word "beudy". ${ }^{1}$

The fall from "the" to "be" is steep and is completed in less than $20 \mathrm{~ms}$; the $\mathrm{L}^{*}$ is marked with a very limited delay, differently from the usual $L^{*}+H$. When the first tone has been completed, the rise does not start immediately: it is preceded by a very long level tone, lasting $200 \mathrm{~ms}$.

\section{Example \#13}

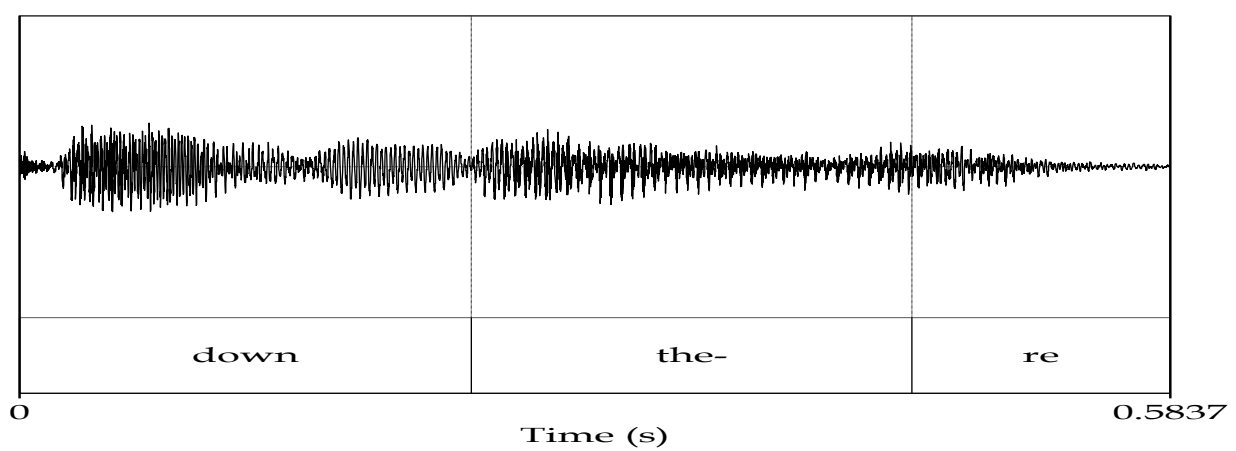

\footnotetext{
1 "beudy"(English "cow-house", "byre") is pronounced [beidi].
} 


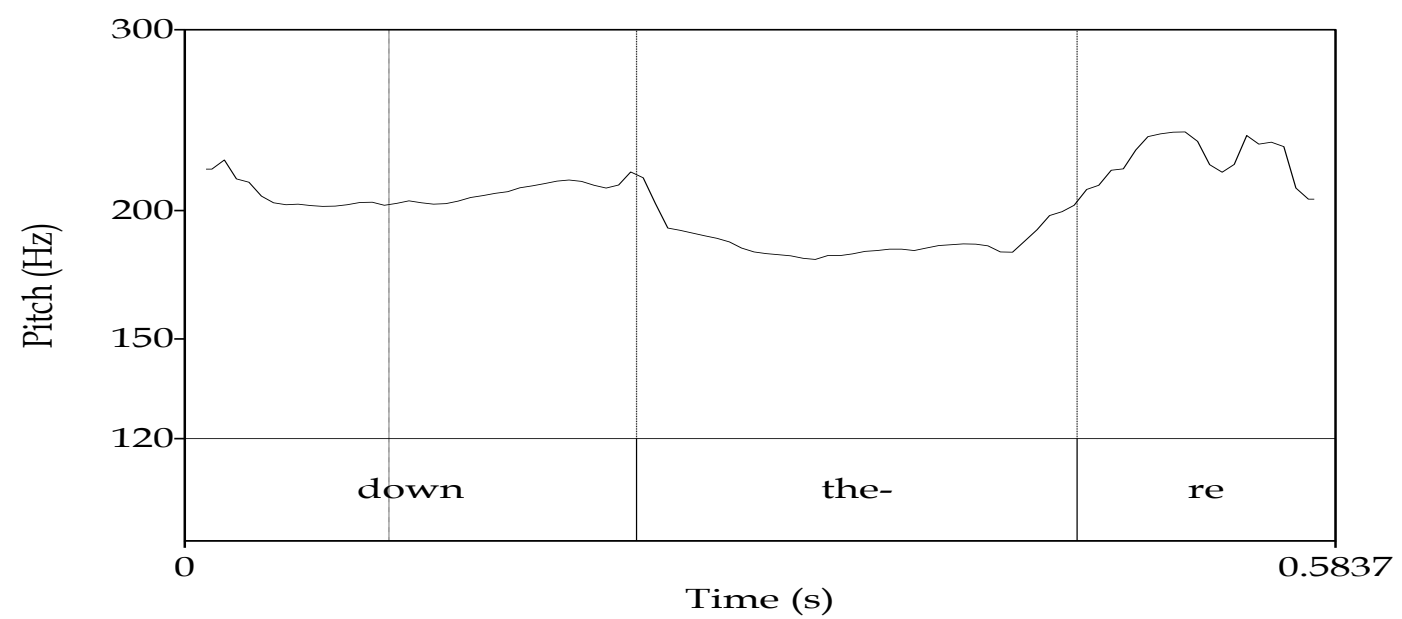

Example \#13 shows an almost identical pattern: the movement towards "there" is rather steep and deep; there is some late alignment of the $L^{*}$, but this is limited to only $35 \mathrm{~ms}$. When the fall is complete, there is a long static tone, which lasts $129 \mathrm{~ms}$, and precedes the rise.

What emerges from these examples on $\mathrm{L}^{*}+\mathrm{H}$ pitch accent is that the $\mathrm{H}$ tone is always steady, regardless of the preceding $L^{*}$, and there are no effects which can be compared to the sags of $\mathrm{H}^{*}+\mathrm{H}$. Usually, the average length of the upward movements is 80-90 ms, although it is difficult to be more precise.

\section{Pitch peak}

The final part of the analysis on pitch accents will focus briefly on the pitch peak: here the goal is to determine the position of the highest pitch within an utterance. The analysis of CE has presented the following data: in most pitch accents carrying a rising second tone (regardless of the nature of the first one), the pitch peak is reached towards the end of the word, with a percentage which can vary between $80 \%$ and $90 \%$ into the syllable. ${ }^{2}$

\footnotetext{
${ }^{2}$ The percentage is calculated from the start of the initial vowel of the first syllable, thus the possible preceding consonant is not considered.
} 
Pitch peak and intensity peak do not always occur at the same moment: on some occasions, the final $\mathrm{H}$ is heavily stressed and more intense than the previous contour point, which leads to an almost perfect union between pitch peak and intensity peak. In certain other cases, the $\mathrm{H}$ is softer, the pitch peak being aligned much later than the intensity peak. In $\mathbf{H}^{*}+\mathrm{L}$, the pitch peak usually occurs at the same time of the intensity peak (or with a very limited delay), as has been shown in the previous examples.

\section{Conclusions}

This final chapter will review all the elements which have been presented in the previous pages. Welsh English, similarly to other Celtic Englishes, have a preference for rising tones. However, it is necessary to show the main characteristics of rising tones and determine how they are developed: using PRAAT or similar software is fundamental, since they reproduce the pitch movements and allow the researcher to determine the beginning and the end of each tone, but more importantly how they are developed; the questions on alignment which have been proposed during in the previous sections are a necessary step in order to underline this distinguishing feature of a variety of English.

Walters (1999) prepared a similar analysis on RVE, and came to similar results: even in the southern variety of Welsh English upward movements are seldom swift, but they usually present at least one of the following characteristics:

- The upward movement towards the stressed syllable is usually introduced by a long level tone, which delays the actual rise.

- The two contour points of a pitch accent are often joined by a sag, which is a curve in the F0. The initial movement after the stressed syllable is not upward, but downward: the real rise does not start until the pitch has reached a low position in the speaker's range.

Even the analysis of the pitch peak has shown some similarities between RVE and CE: the comparison between the present findings and those of Walters' might suggest 
that the position of the pitch peak could be one common distinguishing feature of Welsh English in general; confirmation of this hypothesis, however, could only be established by future research on other varieties of WE.

\section{References}

Boersma, Paul \& David WeENINK (2008) Praat: Doing phonetics by computer (version 5.0.32) [Computer software], Retrieved $12^{\text {th }}$ January 2010, from [http://www.praat.org/].

CRUTtEnden, Alan (1995) "Rises in English", in J. Windsor Lewis (ed.), Studies in General and English Phonetics, London and New York: Routledge, 155-173.

GIMson, A. C. (2008) The Pronunciation of English, London: Hodder Education.

LADD, D. Robert (2008) Intonational Phonology. 2nd Edition, Cambridge: Cambridge University Press.

PARRY, D. (ed.) (1977-1979) Survey of Anglo-Welsh Dialects, 2 volumes, Swansea: privately published.

TeNCH, Paul (1990) "The Pronunciation of English in Abercrave", in N. Coupland (ed.), English in Wales. Diversity, Conflict and Change, Clevedon: Multilingual Matters, 130-141.

WALTERS, J. Roderick (1999) A study of the segmental and supra-segmental phonology of Rhondda Valleys English, PhD Thesis, University of Glamorgan, Pontypridd, Wales. Condensed version published on-line by the University of Glamorgan (2006), $<$ http://resnt1.isd.glam.ac.uk/rhondda_valleys_english/> (accessed $10^{\text {th }}$ January 2011). 